\title{
Patents running out: time to take stock of robotic surgery
}

\author{
Barry A O'Reilly
}

Received: 4 February 2014 / Accepted: 7 February 2014 / Published online: 28 February 2014

(C) The International Urogynecological Association 2014

\section{The past}

Throughout history there have been descriptions of machines designed to function automatically, with one of the earliest descriptions of a self-operating machine or automaton appearing in the Liezi text in the third century B.C.

The word robot comes from the Czech robota, meaning "servitude, forced labor," and was first introduced to the English language by Czek playwright Karel Capek in 1921 in his science-fiction-based play R.U.R - Rossums Universal Robots.

The twentieth century brought a dramatic increase in robotic innovation, including technologies such as telemanipulation or telepresence - the ability to operate or manipulate a device remotely. In 1942, Robert A. Heinlein wrote a science fiction short story titled Waldo, describing a glove and harness device that allowed the lead character, Waldo Farthingwaite-Jones (a frail and weak young boy who was unable to lift his own body weight) to control a powerful mechanical arm by simply moving his hand and fingers. About 10 years after this publication, variations of remote manipulators (popularly known as waldos) were developed in the real world for moving and manipulating hazardous materials. Raymond Goertz, an early pioneer in the field of robotics, developed the first master/slave manipulator in order to handle radioactive material while he was working for the Atomic Energy Commission.

Significant developments in telepresence occurred in the 1980s because of the advances in microelectronics and computing, so that master/slave technology was now being used in other hazardous environments, such as ocean salvage and

B. A. O'Reilly $(\bowtie)$

Department of Urogynaecology, Cork University Maternity Hospital, Cork, Ireland

e-mail: barry.oreilly@hse.ie exploration and in outer space. Simultaneously, there were enormous advances in surgery with the first laparoscopic procedures being developed, culminating in the first laparoscopic cholecystectomy performed in 1985 by Erich Mühe from Germany, who faced widespread cynicism at the time for his key-hole surgical approach [1]. Soon after this landmark surgery, laparoscopic technology and techniques boomed and continued to gain adoption into the 1990s for simple surgical procedures. However, the applications for laparoscopic surgery began to stall in the 1990s, as it became apparent that the technical skill set and ergonomic difficulties involved in advanced laparoscopic surgery were significant obstacles for many maximally invasive surgeons.

In the late 1980s, the Defense Advanced Research Projects Agency (DARPA) funded several academic institutions to research the possibility of a remote surgery program targeted at battlefield triage. As a result of these collaborations, the telepresence surgery system was developed. Intuitive Surgical was founded in 1995 and secured licenses on the technologies developed by several of these institutions, thus launching the da Vinci Standard in 1999. This platform was able to overcome the limitations of traditional laparoscopy by giving surgeons $3 \mathrm{D}$ vision, EndoWrist ${ }^{\circledR}$ instrumentation (7 degrees of freedom instrument wrist action), and Intuitive ${ }^{\circledR}$ motion. This initial standard da Vinci system had very simple instruments that were not procedure-specific. In 2003, Intuitive Surgical offered a fourth arm in an upgraded system, allowing the surgeon the ability to control retraction and move control from arm to arm. In 2006, high-definition (HD) vision was introduced in robotic surgery; in 2009, the Si System was launched featuring a dual console for joint operating and training. Future advancements include use of fluorescent agents that attach to specific antibodies to enable fine dissection of cancerous margins and perhaps a flexible microscope that can be manipulated with da Vinci instruments in order to examine tissue in vivo, allowing immediate histopathological 
assessment so that a surgeon could operate in real time with precise knowledge of tissue histology. Other advances include network capability so that remote diagnostics and system checks enhance instrument efficiency, and measurement of procedure metrics enhances surgeon efficiency.

\section{The present}

As of 30 September 2013, there were 2,871 units installed worldwide: 2,042 in the United States, 455 in Europe, and 374 in the rest of the world; however, there certainly appears to be a global slowdown in the sale of da Vinci robotics. This is probably due to a saturation of installations over the last few years, which has resulted in a large reduction in new systems sold worldwide and especially in the USA. The demand from hospitals looking at new installations is to embark on a full multi-specialty program that involves all surgical disciplines currently using a robotic platform: urology, gynecology, earnose-throat, cardiothoracic, vascular, plastics, colorectal, and bariatrics.

Single-site, or port surgery, has gained popularity, offering patients a surgical approach via a single site, often hidden in the umbilicus, thus minimizing or eliminating visible scars. However, the limitations of laparoscopic surgery-such as 2D vision, an unstable endoscope, and counterintuitive control-are still problematic and can make the working space for the surgeon more cumbersome, which is the reason that robotic platform manufacturers are developing a tool that has all the advantages of existing robotic platforms but through a single port.

The single prohibitive factor in a continued global uptake of robotics in surgery is the capital cost-both the initial outlay and the continued costs of both instruments and service agreements. According to recent estimates, Intuitive Surgical has noted a significant reduction in sales over the last 2 years, but despite this, the company's estimates indicate that devices are being used more, which has resulted in a $6 \%$ increase in revenue from instrument and accessory sales (Bloomberg. com). This reduction in robot sales in the USA is probably due to a change in hospital spending priorities driven by the Affordable Care Act (ObamaCare) and also by the recent concerns raised by the American Congress of Obstetricians and Gynecologists (ACOG) and in the growing number of da Vinci lawsuit filings. In its last quarterly earnings statement, the company revealed that the surgical robot had been named in 50 product liability claims filed on behalf of patients who allegedly suffered serious surgery complications due to the device. This particular issue highlights the importance of training and credentialing that should be in place with any new technology and, in many ways, it echoes the issues involved in the transvaginal mesh debacle. In 2004, the Society of American Gastrointestinal and Endoscopic Surgeons (SAGES) launched the validated Fundamentals of
Laparoscopic Surgery (FLS) curriculum and, together with the American College of Surgeons (ACS), promoted the FLS as a minimum standard before a surgeon should be allowed to perform laparoscopic procedures independently [2]. Similarly, expert robotic surgeons and numerous surgical societies and certifying organizations have advocated the need for the creation of a unified approach and standardized curriculum for basic training and certification in robotic surgery skills. A series of consensus conferences attended by 14 leading international surgical societies that addressed outcomes measures and a curriculum that should form the basis for a Fundamentals of Robotic Surgery (FRS) program was recently published [3]. The development of a multispecialty FRS is essential for the safe conduct of robotic surgery and will form the basis for the future of minimally invasive surgery.

It is important at this stage to acknowledge that the current robotic system is simply a surgical tool, and this should raise the issue as to whether randomized controlled trials are necessary in evaluating a surgical tool. The difficulties of recruiting for an RCT comparing robotic with traditional approaches were outlined in an editorial in this journal. The editorial focused particularly on the roles of patient, physician, and hospital bias [4]. A health technology paper in the late 1980s observed that with new technologies: "it's always too early to do a randomized controlled trial until it's suddenly too late" [5]. Whereas an RCT is considered the ultimate in surgical assessment, the Idea, Development, Exploration, Assessment, Long-term study (IDEAL) framework describes the stages of evaluation for surgical innovations and considers the role of collaborative multicenter observational studies in the exploration and assessment stages, which can form the basis for identifying important patient characteristics, technical intervention variables (including potential cointerventions), and clinical outcomes of interest [6].

Aside from the traditional robotic platforms, there is a growing emergence of technological innovations that offer all the advantages of the robotic degrees of freedom (EndoWrist) and manipulation but using, instead, a standard laparoscopic approach and instrumentation but at a much reduced capital outlay (e.g., Dexterite Surgical). These systems can be allied with 3D laparoscopic technology, which is widely available in many hospital operating rooms.

\section{The future}

However, over the last 10 years, patents have expired, and many companies around the world are at various stages of robotic surgical technology development. Intuitive Surgical have been able to command such enormous costs because of its monopoly position as sole supplier of the da Vinci. As with any economic model, competition will bring down costs, and there will certainly be a number of new robotic manufacturers 
entering the market over the next couple of years (e.g., Titan Medical and Kymerax). A recent paper emphasized the importance of international competition commissions and to "balance monopoly with monopsony - the formation of a single buying power," which may only be possible in countries with a unified healthcare provider system [7].

There is also an emerging market in preowned systems, with some companies offering 4-year-old systems at around $75 \%$ lower price points. It has been estimated that the preowned market will allow at least four times the number of surgical centers to enter the robotic world. If this type of surgery is controlled in a well-audited fashion, then both patients and surgeons will benefit. I always enjoy reading the "Mentors in Urogynecology" section in the International Urogynecology Journal [8], and the following quote from Ray Lee best summarizes why we must embrace robotics and the future:"I'm convinced surgeons are made and not born. Be an active learner for the rest of your life. Most importantly, commit yourself to staying up to date in this fast-changing arena."

Financial Disclaimers/Conflict of interest None.

\section{References}

1. Litynski GS (1998) Erich Mühe and the rejection of laparoscopic cholecystectomy (1985): a surgeon ahead of his time. JSLS 2(4): 341-346

2. Peters JH, Fried GM, Swanstrom LL, Soper NJ, Silin LF, Schirmer B, Hoffman K, SAGES FLS Committee (2004) Development and validation of a comprehensive program of education and assessment of the basic fundamentals of laparoscopic surgery. Surgery 135(1):21-27

3. Smith R, Patel V, Satava R (2013) Fundamentals of robotic surgery: a course of basic robotic surgery skills based upon a 14-society consensus template of outcomes measures and curriculum development. Int J Med Robot. Nov 26 [epub ahead of print]

4. Collins S, Tulikangas P (2010) Randomized trials in robotic surgery: a practical impossibility? Int Urogynecol J 21(9):1045-1047

5. Buxton MJ (1987) Problems in the economic appraisal of new health technology: the evaluation of heart transplants in the UK. In: Drummond MF. Economic appraisal of health technology in the European Community. Oxford Medical Publications 103-18

6. Ergina PL, Barkun JS, McCulloch P, Cook JA, Altman DG (2013) BMJ IDEAL framework for surgical innovation 2: observational studies in the exploration and assessment stages. BMJ 346:f3011

7. Trehan A, Dun TJ (2013) The robotic surgery monopoly is a poor deal. BMJ 347:f7470

8. Gehart J (2013) Ray Lee, 1931-2012:surgeon, teacher, mentor, friend. Int Urogynecol J 24(8):1257 